\title{
O Movimento pela Escola Nova no Paraná: trajetória e idéias educativas de Erasmo Pilotto
}

\author{
Movement for New School in Paraná: \\ trajectory and educational ideas of Erasmo Pilotto.
}

\author{
Carlos Eduardo Vieira $\bullet$
}

\begin{abstract}
RESUMO
Este artigo se propõe a produzir uma história intelectual do Movimento pela Escola Nova no Paraná, a partir da análise da trajetória e das idéias educativas de Erasmo Pilotto. Metodologicamente o estudo explora o conceito gramsciano de intelectuais, visando discutir o movimento renovador como um campo de disputas entre diversos projetos formativos. O período está delimitado entre 1920 e 1960 e as fontes desse estudo são obras publicadas e manuscritos inéditos deste intelectual paranaense.
\end{abstract}

Palavras-chave: Intelectuais; Escola Nova; Erasmo Pilotto.

\begin{abstract}
This article proposes to produce an intellectual history of Movement for New School in Paraná, covering the trajectory of educative ideas of Erasmo Pilotto. Methodologically, this research explores Gramsce`s conception of intellectuals, intending to discuss the renovator movement as a disputing field among many other educational projects. The period is delimited between 1920 and 1960; the sources of this research are published works and manuscripts of this Parana's intellectual.
\end{abstract}

Key words: Intellectuals, New School, Erasmo Pilotto

- Doutor em História da Educação, Professor da Área Temática de História e Historiografia da Educação do Programa de Pós-graduação em Educação, da Universidade Federal do Paraná. cevieira@educacao.ufpr.br. 


\section{Introdução}

O estudo sobre a trajetória e a obra do intelectual paranaense Erasmo Pilotto se insere entre as iniciativas desenvolvidas pela Área Temática de História e Historiografia da Educação, do Programa de Mestrado e Doutorado em Educação, da Universidade Federal do Paraná. Esta pesquisa é parte de um projeto mais amplo desta área temática que visa colaborar com o empreendimento científico de produzir conhecimento histórico sobre intelectuais, instituições e cultura escolar no Paraná.

A intervenção de Pilotto na cultura paranaense constitui um fenômeno de grande proporção, acompanhar a sua trajetória implica em analisar um percurso marcado por inúmeras inserções: da pedagogia às artes plásticas, da filosofia à literatura. Leitor de filósofos e literatos como Spinoza, Nietzsche, Tolstoi, Rousseau, Goethe, entre outros, ele se notabilizou pelos estudos e pelas suas realizações no campo da cultura paranaense em geral e, particularmente, no âmbito da organização da escola pública e da formação de professores. Nesse sentido, delimitaremos esse artigo à análise de seu papel na introdução e na disseminação do Movimento pela Escola Nova no Estado, enfatizando as bases teóricas da concepção de formação humana que ele produziu a partir de sua interlocução com o movimento renovador.

Utilizarei, ao longo do texto, a expressão Movimento pela Escola Nova para me referir, em sentido amplo, ao movimento cultural que, na década de trinta do século passado no Brasil, mobilizou um conjunto significativo de intelectuais brasileiros em torno de um projeto que, nas palavras de Lourenço Filho, visava a organização nacional através da organização da cultura. Parto da premissa de que a atuação dos intelectuais envolvidos com o movimento foi decisiva na configuração do campo educacional brasileiro, a partir de suas iniciativas na definição de políticas públicas para educação, na organização do sistema nacional de ensino, na reformulação dos métodos pedagógicos, bem como na orientação da formação de professores. ${ }^{1}$

Assumimos como hipótese de trabalho que a concepção formativa elaborada e sustentada por Pilotto se insere, no âmbito do movimento renovador, a partir de uma concepção espiritualista do processo educativo que, em termos teóricos, contrasta com o ethos cientificista que predominou entre os principais protagonistas do movimento em nível nacional. Entendo por espiritualismo o tipo de concepção teórica e, sobretudo, filosófica que

1 Trata-se do discurso de Lourenço Filho, expoente do movimento renovador, na seção inaugural da VII Conferência Nacional de Educação, de 1935, citado por Marta Maria Chagas de Carvalho, em $O$ território do consenso e a demarcação do perigo: política e memória do debate educacional dos $\operatorname{anos} 30$, p. 22. 
pratica a filosofia como análise da consciência e/ou que assume como objetos da reflexão filosófica os dados da consciência, advogando, em contrate com a idéia de determinação natural ou social, a liberdade, a autonomia e a responsabilidade das ações humanas.

Creio que chamar a atenção para essa dimensão de seu pensamento contribui para a compreensão da multiplicidade de idéias e de referências teóricas que compuseram o Movimento pela Escola Nova no Brasil. A literatura educacional e pedagógica, em geral, tende a eclipsar essa pluralidade de idéias em favor de uma compreensão homogeneizadora, que remete para um único endereço teórico, denominado genericamente pensamento escolanovista, um conjunto de intelectuais que produziram itinerários teóricos muito diversificados e, muitas vezes, contraditórios e irreconciliáveis entre si.

A opção de investigar as idéias e as trajetórias dos intelectuais apresenta-se, no debate metodológico, em oposição ao tipo de história das idéias desencarnadas ou à forma biográfica, interessada no culto personalista de expoentes das letras e da cultura. Portanto, é uma perspectiva que objetiva estabelecer os nexos, as relações entre os intelectuais, as correntes de pensamento e o seu meio social. Investigamos os intelectuais porque consideramos que as suas idéias e as suas trajetórias são testemunhos privilegiados dos diversos projetos formativos que demarcam as disputas em torno da direção dos processos de formação das novas gerações. Nesse sentido, nos propomos a produzir uma história intelectual do movimento renovador no Paraná, a partir da análise da trajetória daqueles que ocuparam as funções de direção e de organização do movimento. ${ }^{2}$

A decisão de investigar o papel dos intelectuais tem a sua referência teórica na obra de Antonio Gramsci, que considera como intelectuais todos aqueles que participam ativamente da direção e da organização dos projetos culturais que visam intervir sobre o modo de vida e o processo de formação humana. Para Gramsci um movimento social "não se 'distingue' e não se torna independente 'de per si', sem organizar-se (em sentido lato) e não existe

2. A expressão idéias desencarnadas é do historiador francês Lucien Febvre em crítica aberta à forma com a filosofia trabalha com as idéias. Sobre essa questão ver, entre outros, CHARTIER, Roger. O passado composto: relações entre filosofia e história. In: A história cultural: entre práticas e representações. Lisboa: Difel, 1990. p.69.-89. Robert Darnton, na difícil tarefa de classificar os gêneros de pesquisa histórica que discutem as formas de pensamento, chama de história intelectual a espécie de trabalho que visa discutir "os climas de opinião e os movimentos literários” (DARNTON, 1990, p.188). Sem nenhuma pretensão de discutir a classificação oferecida por Darnton, diria que a ampliação do conceito para os movimentos e tendências culturais em geral, possibilitaria, sem constrangimentos, assumir essa denominação como a mais adequada para classificar o tipo de investigação empreendida neste artigo. 
organização sem intelectuais, isto é, sem organizadores e dirigentes" (GRAMSCI, 1977, p.1386).

São os intelectuais os principais responsáveis por traduzir em termos teóricos e, sobretudo, nos marcos de um plano de ação política os objetivos almejados pelos diferentes grupos e classes sociais que disputam a hegemonia na sociedade, isto é, as funções de domínio e de direção cultural. A associação entre política e cultura no pensamento de Gramsci não resulta na afirmação da supremacia do plano cultural e ideológico sobre o econômico e o social, mas sim na compreensão da cultura como lugar de síntese, de manifestação das contradições e dos antagonismos que permeiam a vida social.

A expressão racionalizada dessas contradições conduz a julgamentos, produz significados, define valores e indica condutas que se inscrevem em visões de mundo com maior ou menor grau de coerência teórica, de capacidade de produzir identidades coletivas e de competência para mobilizar os homens em torno de determinados fins. No centro dessa atividade estão os intelectuais, que não são juizes, nem engendradores dos movimentos sociais, mas representantes qualificados que assumem as funções de direção e de organização desses movimentos. A rigor, essa concepção contrasta com a representação tradicional do intelectual como erudito desinteressado, como clérigo, na expressão celebrizada pela obra de Julien Benda. ${ }^{3}$ Ela enfatiza o que a concepção tradicional considerava a negação da postura do intelectual, isto é, a intervenção política.

O conceito gramsciano enfoca as diversas dimensões do trabalho intelectual, de tal maneira que a produção, a disseminação, bem como as funções de direção e de organização dos projetos sociais são consideradas como partes do trabalho intelectual. Logo, nessa perspectiva, é preciso ampliar o conceito de atividade intelectual para compreendermos os complexos processos de domínio e de direção cultural. As análises sobre a unificação do Estado italiano na segunda metade do século XIX e sobre o contexto europeu do primeiro quartel do século vinte, particularmente o exame do malogro da revolução socialista nos países da Europa ocidental levaram Gramsci a estas reflexões sobre a função social dos intelectuais, sua crescente tendência à especialização e à associação em torno de instituições, movimentos sociais, periódicos, partidos, enfim, organismos coletivos que passaram a se sobrepor às grandes individualidades da cultura e da política.

O que é essencial nesse conceito é que não existe nenhum a priori de formação e/ou posição institucional para definir o intelectual. Cabe sempre ao investigador interessado na sua exploração analisar a natureza dos projetos

\footnotetext{
3 Trata-se da obra La trahison des clercs, de 1927.
} 
formativos em curso, a ação dos seus protagonistas e, sobretudo, avaliar em contexto as conseqüências sociais destes projetos. É um conceito eminentemente histórico, uma vez que em termos abstratos ele é tão abrangente que dificilmente assumiria uma significação precisa. A ênfase sobre a função social em relação à formação cultural ou o destaque sobre a organização da ação política em relação à produção teórica são aspectos ainda muito genéricos para uma definição rigorosa. Dessa forma, no âmbito da pesquisa histórica, o conceito é permanentemente reconstruído, de maneira a identificar e analisar, nos seus devidos contextos, quem exerceu as funções dirigentes, quais eram seus fins e quais estratégias e meios foram utilizados.

A participação dos intelectuais na esfera pública não é prerrogativa de uma sociedade, de um país ou de um momento histórico específico. Não obstante, é preciso compreender a historicidade do conceito para circunscrever a sua utilização. Michel Winock, tomando como referência a França, assevera que em 1898, por ocasião da manifestação dos homens de letras e de cultura no caso Dreyfus, inaugura-se o sentido contemporâneo do termo intelectual. Para este autor o conceito visa evidenciar a presença dos intelectuais na cena pública e, secundariamente, suas idéias ou obras literárias, poéticas e científicas (WINOCK, 1997, p.9). Acrescentaríamos a esse raciocínio, visando mais precisão conceitual, a questão da presença dos intelectuais como tendência cultural ou grupo social que produz a sua identidade à medida que avoca uma responsabilidade, função ou missão social específica. $\mathrm{O}$ termo, nesse quadro teórico, deve necessariamente ser grafado no plural, pois, mesmo em um estudo que vise analisar a trajetória de um intelectual em particular, a ênfase deve recair sobre o grupo ou movimento com o qual ele se identificou e produziu as suas inserções na cena pública como parte de uma elite pensante, comunidade de técnicos, militantes de vanguarda, philosophes esclarecidos, intelligentsia, enfim de acordo com as várias denominações e autodenominações que os intelectuais assumiram ou com que foram representados em diferentes circunstâncias históricas.

É sobre estas bases conceituais que visamos compreender a trajetória e as idéias de Pilotto como partícipe do Movimento pela Escola Nova no Brasil, como expressão paranaense do movimento que produziu formas de pensar e de atuar na esfera educacional brasileira que permanecem repercutindo intensamente, seja no plano das práticas de ensino, das teorias educativas, das políticas ou das formas de administração da educação no Brasil. 


\section{Os Intelectuais e a Causa da Educação: As Origens do Movimento pela Escola Nova no Paraná}

Os estudos MICELI (1979), PÉCAULT (1989), LAHUERTA (1997), CARVALHO (1998) enfatizam, guardadas as devidas diferenças temáticas e metodológicas, os anos vinte do século passado como um período de intensificação da presença da intelectualidade brasileira na cena pública. $O$ clamor pela modernização, a afirmação dos valores e das instituições republicanas, a causa da educação do povo e da formação das elites dirigentes são temas que amalgamaram correntes e tendências culturais e produziram a atmosfera intelectual do período.

O sentimento de missão, a postura de demiurgos da nação e da cultura são características marcantes dos diversos protagonistas desse contexto: católicos, liberais, comunistas compartilhavam convicções sobre o papel das elites intelectuais na construção da nacionalidade brasileira. Sem a pretensão de problematizar essas questões, pois os autores acima citados já o fizeram, considero que, no horizonte dessa missão civilizatória reclamada pelos intelectuais, a questão educacional ocupou uma dimensão sem precedentes. Nesse sentido, os conflitos entre os diferentes projetos formativos significavam, nesse período, disputas entre diferentes projetos nacionais e concepções de modernidade.

No caso específico dos intelectuais vinculados mais diretamente à causa educacional, CARVALHO (op. cit.) destaca a Associação Brasileira de Educação (ABE), fundada em 1924, assim como as suas sucessivas conferências e os eventuais manifestos como os principais púlpitos utilizados pelos intelectuais na perspectiva de veicularem seus projetos. Nesse contexto a igreja católica ocupou espaço significativo, pois gozava de sólidas posições institucionais e tradição de ensino no país, contudo encontrava a resistência crescente de intelectuais laicos que, desde o século XIX, formavam-se na vaga cientificista do positivismo, dos ideais políticos republicanos e que associavam à presença da igreja católica na cultura nacional o atraso, o tradicionalismo, a visão metafísica, etc.

Os vários projetos em disputa apresentavam a educação do povo e o desenvolvimento nacional como as duas faces de uma mesma questão. Formação da nacionalidade, industrialização e modernidade são empreendimentos considerados impensáveis sem o enfrentamento da questão educacional. A atmosfera intelectual dos anos vinte enfatizava a educação como meio privilegiado de constituição da identidade do povo e da nação, bem como de condição para o desenvolvimento econômico e o bem estar social. 
No Paraná a formação de tendências intelectuais em confronto na cena pública remonta aos últimos anos do século dezenove. O intenso debate entre clericais e anticlericais sobre os rumos da república e, por extensão, da educação pública marcaram a imprensa paranaense e a ambiência cultural de Curitiba nas primeiras décadas do século vinte. Nos anos vinte o marco mais representativo desse processo está na realização da Primeira Conferência Nacional de Educação, promovida pelo governo do Estado em associação com a ABE, em dezembro de 1927. ${ }^{4}$

A primeira conferência foi marcada pela presença massiva de delegados paranaenses, uma vez que dos 527 participantes, 504 eram paranaenses de várias regiões do Estado. A segunda maior delegação é a do Rio de Janeiro, com apenas nove delegados (SCHMIDT, 1997, p. 86). A representação desproporcional dos delegados não impediu que a causa $d a$ educação fosse colocada em tela, dando seqüência à campanha promovida pela ABE no Rio de Janeiro.

$\mathrm{Na}$ esfera local, a conferência representou parte do esforço de modernização e de inserção do Estado e, sobretudo, de sua capital no cenário nacional. Sediar a conferência significava estar à frente daquele que era considerado como o principal problema nacional, ou seja: a causa da educação. Na ABE dos anos vinte e na Conferência de 1927, o grupo com maior organização e presença é o católico. Lysímaco Ferreira da Costa, Inspetor Geral de Instrução Publica do Paraná, representante do governo do Estado na conferência e seu principal relator, estava próximo dos católicos que exerciam forte influência sobre o governo de Bento Munhoz da Rocha, no Paraná, e sobre a direção da ABE, no Rio de Janeiro. Logo, nos anos vinte, é um erro associar o Movimento pela Escola Nova com a ABE e, sobretudo, com a Primeira Conferência Nacional de Educação.

Não obstante, a campanha pela causa educacional promovida pela associação e reafirmada pela conferência de 1927 constituiu o terreno de formação do pólo renovador. A demanda pela ampliação do acesso à escolarização na sociedade brasileira, advinda dos mais diferentes estratos sociais, levou o Estado e os diversos grupos políticos que disputavam o poder na sociedade brasileira a cooptarem quadros importantes da intelectualidade para gerirem projetos, instituições e reformas nas políticas públicas para a educação. A luta pela ocupação desses espaços institucionais em Estados e cidades importantes da federação, no âmbito das acirradas disputas que

\footnotetext{
${ }^{4}$ Sobre o embate entre clericais e anticlericais em Curitiba, dos últimos anos do século XIX às primeiras décadas do século XX, ver Carlos Alberto de Freitas Balhana, Idéias em confronto, Curitiba: Grafipar, 1981.
} 
marcaram os anos vinte, levou à cristalização de tendências e projetos educativos antagônicos. 5

A disputa em torno da orientação do sistema público de ensino ganhou dimensões de estratégia de Estado e, assim, ocupou governos e intelectuais de grande representatividade na sociedade brasileira. $\mathrm{O}$ aparente consenso em torno da causa educacional velava conflitos entre diferentes projetos que na década de trinta se tornaram mais nítidos. Entre os episódios mais significativos desse conflito estão o advento do Manifesto dos Pioneiros da Educação Nova e o rompimento do grupo católico com a diretoria da ABE, ambos em 1932 (CARVALHO, 1998, p.112-3). No Paraná, guardadas as especificidades locais, esse confronto recrudesceu. Distante dos cargos de direção no Estado e do cenário da Conferência de 1927, o movimento renovador surge no interior da Escola Normal de Curitiba. A iniciativa de promover o debate das idéias e das práticas escolares que se projetavam no Brasil, a partir de experiências norte-americanas e européias, não partiu de professores ou de intelectuais proeminentes em Curitiba, mas sim de estudantes liderados por Erasmo Pilotto.

\section{Erasmo Pilotto e a Escola Nova no Paraná ou o duro problema da coerência}

Em contraste com a maioria dos jovens curitibanos de seu meio social, Pilotto optou por ser professor primário. Em depoimento nos anos oitenta, afirmou que esta decisão sofreu redefinições ao longo de sua trajetória e argumenta que não foi "diretamente o 'mestre de meninos', mestre escola, mas toda a [sua] vida foi o sincero serviço, sem interrupção de um dia, à causa da educação. O duro problema da coerência”. (PILOTTO, 1989, 12b).

A coerência e a causa da educação levaram-no, em 1927, aos bancos da Escola Normal de Curitiba. Encontra o curso de formação de professores saturado pelo formalismo herbatiano que, na sua expressão, em nada representava o sério exercício de Herbart de interpretar a cultura pedagógica alemã. $\mathrm{O}$ ensino estava baseado em adaptações apostilares áridas da concepção educacional herbartiana que, longe de estimular a criatividade e a reflexão, primava pela repetição mecânica de preceitos pedagógicos abstratos.

A reação à versão vulgarizada do pedagogo e filósofo alemão foi inevitável, uma vez que o jovem estudante, mesmo antes do ingresso na

5 Sobre as demandas crescentes por escolarização no Brasil da segunda metade do século dezenove à primeira do século vinte ver, entre outros, o significativo estudo realizado por Marcus Levy Albino Bencostta et al. Memórias da educação: Campinas (1850-1960). Campinas: UNICAMP, 1999. 
Escola Normal, havia realizado leituras que marcariam profundamente a sua reflexão sobre a educação, em particular Tolstoi e a sua experiência pedagógica na Escola Yasnaia-Poliana, bem como Rousseau e o seu Emílio. Ao entrar na Escola Normal ele relata que "já estava com os pés plantados na Escola Nova [e daí em diante] afundei nas idéias do grande movimento". (PILOTTO, p.43).

Nesse período, Pilotto conheceu o Professor de História Geral Dario Vellozo que - em ásperas divergências com as autoridades educacionais do Estado, particularmente com Lysímaco Ferreira da Costa - sustentava a necessidade de impedir que os jovens fossem constrangidos à influência da Igreja Católica. Em um duro debate promovido nas páginas da imprensa paranaense Vellozo defendia, de forma radicalizada, o anticlericalismo, o nacionalismo e os ideais republicanos. No plano educacional propôs e realizou, a partir de escolas experimentais, o projeto de implantação da Escola Moderna. Esse projeto não deve ser interpretado como o antecedente do Movimento pela Escola Nova no Estado, mas sem dúvida foi responsável pela afirmação de princípios que, posteriormente, foram incorporados pelo movimento renovador, tais como a laicização, a publicização e a universalização do ensino básico. ${ }^{6}$

Nessa atmosfera - marcada pela força dos católicos na administração pública e pela presença de grupos republicanos e anticlericais radicalizados pelas concessões do Estado Republicano à Igreja Católica foram criados em Curitiba, com a ativa participação de Pilotto, o Centro de Cultura Filosófica, o Centro de Cultura Pedagógica, a Universidade Popular, bem como o boletim intitulado O Ideário da Escola Nova. Entre os anos de 1927 e 1930 estes círculos de cultura visaram a divulgação dos ideais da Escola Nova, bem como formar intelectuais comprometidos com a renovação das práticas e das teorias pedagógicas.

A causa educacional nos anos vinte propiciou a mobilização e a constituição dessas tendências intelectuais, contudo a presença destas no cenário nacional e local obedeceu a dinâmicas específicas e a estratégias diferenciadas. No Paraná os católicos atuaram intensamente através da chamada boa imprensa e do Círculo de Estudos Bandeirantes, obtendo resultados significativos na configuração do campo educacional paranaense, particularmente na implantação do ensino superior na capital e de diversos colégios confessionais, bem como na preservação dos interesses da educação

\footnotetext{
6 Sobre o projeto da Escola Moderna no pensamento e na trajetória de Dario Vellozo, Maria Lúcia Andrade desenvolve dissertação, sob minha orientação, que deverá ser defendida até agosto de 2002.
} 
católica nas políticas públicas para educação. ${ }^{7}$ Já o projeto dos renovadores, inicialmente adstrito a pequenos círculos de cultura, boletins de pequena circulação e instituições de ensino experimentais, ganhou força respaldado pelo quadro nacional e internacional favorável à renovação dos métodos e dos objetivos da escolarização. As mudanças no quadro nacional, marcado pela ascensão dos renovadores na diretoria da $\mathrm{ABE}$ e pela presença de intelectuais desse grupo em cargos estratégicos da administração pública brasileira, fortaleceram a posição dos renovadores no Paraná e, assim, projetaram Pilotto como liderança local e referência nacional do movimento no Estado.

\section{Convergências programáticas e divergências teóricas: o espiritualismo no campo das disputas do Movimento pela Escola Nova}

A obra A formação do Professor e a Organização do Trabalho, de Maria Elisabeth Blank Miguel, não visa investigar especificamente as idéias de Pilotto, porém a autora demonstra que é difícil discutir a questão da formação de professores no Estado sem abordar as idéias daquele que esteve, a partir de 1938, à frente desse processo no Paraná. O estudo sinaliza para uma complexa trama de vertentes teóricas que permearam a sua formação e a orientação teórica de seu trabalho, entre as quais o neo-idealismo italiano de Gentile, o neopitagorismo de Vellozo, o positivismo, o humanismo clássico, as idéias de Wallon e Pestalozzi, entre outras referências menos citadas.

$\mathrm{O}$ resultado dessa variedade de referências teóricas expressa-se no seguinte juízo da autora: "Finalmente resta-nos dizer, a respeito de Pilotto, que ele caracterizou-se como um educador eclético, buscando encontrar naqueles que lhe serviram de modelo melhores formas de realizar a educação pública" (MIGUEL, 1997, p.109). Em estudo anterior, O significado do trabalho de Erasmo Pilotto no cenário educacional paranaense, conclui que ele "foi sempre um idealista e é até possível afirmar que aproximou-se muito mais de Hegel" (MIGUEL, 1994, p. 88).

Se entendermos por ecletismo a "diretriz filosófica que consiste em escolher, dentre as doutrinas de diferentes filósofos, as teses mais apreciadas, sem se preocupar em demasia com a coerência dessas teses entre si e com a sua conexão aos sistemas de origem" (ABBAGNANO, 1998, p.298), Pilotto

\footnotetext{
${ }^{7}$ Sobre a implantação de colégios confessionais católicos em Curitiba, ver TRINDADE E. M. de C., Clotildes ou marias - mulheres de Curitiba na Primeira República. Curitiba, Fundação Cultural, 1996. Sobre a intervenção dos intelectuais católicos na constituição de círculos de cultura católica e de projetos educativos em Curitiba, entre as décadas de vinte e quarenta do século vinte, Névio de Campos desenvolve dissertação, sob minha orientação, que deverá ser defendida até agosto de 2002.
} 
não pode ser incluído neste conceito. A amplitude de sua interlocução, o seu estilo livre-pensador não resultou em diletantismo ou falta de rigor intelectual. $\mathrm{O}$ seu pensamento, independente do juízo que possamos fazer dele, tem uma unidade e uma coerência lógica que permite ao historiador verificar, em diferentes fases de sua produção intelectual, a presença de determinadas categorias de pensamento que articulam toda a sua produção intelectual.

Sobre o segundo juízo, certamente Pilotto não se filiava às vertentes materialistas, porém classificá-lo genericamente como idealista não permite uma compreensão precisa de sua concepção filosófico-formativa. A questão metodológica que se impõe na análise de uma trajetória intelectual não se esgota na identificação das interlocuções estabelecidas e nas asserções sobre possíveis influências ou empréstimos teóricos e conceituais entre os diferentes protagonistas da história intelectual e das idéias. Creio que é necessário compreender a dinâmica de elaboração do pensamento como um diálogo singular que expressa relações irredutíveis entre o indivíduo e o seu contexto, ou seja: entre o intelectual, suas fontes, as questões que perpassam a sua ambiência cultural e o seu projeto intelectual.

Pilotto evitou as classificações de seu pensamento, pois "definir e definir-se com a marca, a seita, o uniforme, a libré, a bandeira, a flâmula sagrada [...] é, apenas e bem, um dos caracteres da massificação na vida contemporânea, a massificação enquanto indominada e então má" (PILOTTO, 1973, p.255). Evitar as classificações rígidas, assim como procedem as ciências naturais com as pedras ou os insetos, não significa eximir-se da análise das formas de pensamento, dos processos de recepção e de apropriação de idéias e teorias no interior de um movimento cultural, político etc. Sendo assim, interessa-nos indicar a expressão teórica que historicamente assumiu o Movimento pela Escola Nova no Paraná a partir da leitura realizada por este intelectual paranaense. Não visamos discutir aqui o impacto dessa concepção formativa sobre as práticas educacionais, pois associar as dimensões do pensamento e das práticas envolve um tratamento metodológico específico.

No plano da trajetória intelectual de Pilotto verificamos que a referência às idéias de Tolstoi e Rousseau, assim como às atividades no Centro de Cultura Pedagógica e no boletim $O$ ideário da Escola Nova evidenciam as primeiras aproximações desse intelectual com o movimento renovador. Nos anos trinta esse compromisso se intensificou propiciando sua colaboração com Cecília Meireles, signatária do célebre Manifesto de 1932, nas páginas do Diário de Notícias dirigidas aos professores. Atua na V Conferência Nacional de Educação, como delegado do Paraná, nos debates que preparavam as teses da ABE para o anteprojeto da Constituinte de 1934. Contudo, apesar de demonstrar convergência com vários objetivos do 
movimento e, em particular, apreço sincero por Fernando de Azevedo e Anísio Teixeira, Pilotto mantém uma postura de independência em relação aos líderes do movimento nacional. Ele afirma que a sua "vocação para a Educação Nova vinha [...] de outras origens; assim, foi com grande independência que respeitamos o ar do importante movimento renovador brasileiro" (PILOTTO, 1989, p.53).

A atmosfera cientificista - que envolveu parte significativa do movimento de renovação do pensamento educacional na Europa e nos Estados Unidos e, sobretudo, alguns dos principais protagonistas do movimento no Brasil, tais como Fernando de Azevedo, Lourenço Filho e Anísio Teixeira não pode ser desconsiderada na elaboração de seu itinerário teórico e, principalmente, no plano prático-político de sua intervenção no campo educacional. Não obstante, creio que a análise da reflexão filosófica e pedagógica de Pilotto permite demonstrar a existência de um projeto intelectual que concebeu o Movimento pela Escola Nova, a partir de marcos teóricos bastante diferenciados daqueles que permearam a formação dos principais intelectuais do movimento em nível nacional, particularmente a sociologia positivista e a filosofia pragmatista norte americana. A rigor, é possível afirmar que, no plano do debate sobre a formação humana, ele se mostrou profundamente interessado em demonstrar os limites do método positivista e da concepção de homem e de cultura presente no pragmatismo.

Pilotto dedica uma obra, em 1954, para discutir o pensamento naturalista que identifica como uma tendência intelectual que surge no final do século XIX e que produziu grande impacto sobre a filosofia e a pedagogia do século vinte. De forma sintética afirma que o naturalismo nos

[...] seus traços principais começa a definir-se assim: a) entusiasmo pela natureza e por todas as cousas da natureza; b) desenvolvimento dos estudos da natureza; c) adoção universal, na esfera do conhecimento, dos métodos das ciências naturais; d) aceitação da excelência da natureza sobre tudo e desejo de conformar-se, em tudo, com ela; e) aceitação dos fins aparentes da natureza como fins da vida humana; f) eliminação dos fins que pretendam transcender à natureza (PILOTTO, 1973, p.294-5).

Entre os autores analisados neste estudo, estão Claparède, Durkheim, Marx, Dewey, entre outros. Independente das restrições que possamos fazer ao termo ou à inclusão deste ou daquele pensador nesse quadro analítico, o raciocínio do autor busca demonstrar que esse movimento é uma reação ao pensamento metafísico e que está interessado em incluir os fenômenos sociais, morais, educativos, políticos na esfera das análises científicas. Em síntese uma virada materialista nas formas de pensar que, através dos projetos desses 
intelectuais, intentava produzir um conhecimento objetivo sobre as coisas do homem e da cultura. No segundo capítulo da obra, discute a irrupção do niilismo na filosofia como resultado do desencantamento promovido pelo naturalismo, à medida que este descortinou a mágica da vida, reduzindo a experiência mundana a consequiências de determinações materiais. Entre os representantes desta posição Pilotto inclui Schopenhauer, Nietzsche e Heidegger.

No último capítulo ele trata da reação positiva ao naturalismo, ou seja, aquela que evita o relativismo e o ceticismo do niilismo, na qual ele incluiu o neotomismo católico, na esfera das filosofias confessionais, mas também os itinerários de Bergson na França e de Gentile na Itália, caracterizando a vertente laica da crítica do cientificismo e do materialismo.

Sobre a concepção educativa de Gentile ele destaca que

[...] toda a educação, por este modo, se converte num processo criador do espírito, do espírito mesmo do educando, 'autônomo desenvolvimento do espírito individual [...] todo o processo da educação se converte numa valorização da autonomia, da individualidade, da liberdade, do sentido eternamente criador, e numa valorização do espiritual, quase diríamos, numa educação inspirada por um espiritualismo ético firmemente definido (PILOTTO, 1973, p.433).

O espiritualismo - tal como se manifestou na Europa nas filosofias de Bergson, Croce e Gentile - não representou uma influência sobre Pilotto, no sentido de uma determinação intelectual, mas tornou-se fonte de interlocução capaz de promover um encontro de horizontes entre as idéias em curso no velho continente - de crítica ao positivismo e de ceticismo em relação ao entusiasmo cientificista - com o itinerário de formação de um intelectual que buscava preservar a sua identidade no âmbito do movimento renovador.

No cerne da sua concepção, intitulada humanismo individualista, estão as idéias de autonomia, individualidade, liberdade e do processo permanente de criação espiritual. Em oposição às vertentes materialistas Pilotto defendeu uma visão espiritualista que concebe que os "problemas materiais dos homens são vivíssimos, mas, se virmos bem, todos os problemas do homem vão ter a problemas da idéia e da vontade, da construção interior, e sem solver a estes não adiantam os mil projetos mais bem sucedidos que têm em vista a vida material" (PILOTTO, 1973, p.146).

Ele explorou filosoficamente o ceticismo e o relativismo em ensaios sobre as idéias de Montaigne, Pírron, Schopenhauer, Hume e Nietzsche. O resultado dessas leituras expressou-se em duas direções: a recusa do niilismo, pela sua incompatibilidade com a categoria vida e, por extensão, com a causa educacional; e, por outro lado, a incorporação do antidogmatismo presente 
nesses pensadores que, no âmbito de seu projeto intelectual, recaiu sobre os intentos das teorias educacionais que, em nome da ciência, reduziram o fenômeno educativo às dimensões de seus objetos de investigação, sejam eles as operações cognitivas ou as interações sociais.

\section{Para Pilotto}

[...] toda indagação atual sobre a natureza do conhecimento científico, que sabe que, no máximo, apenas podemos provar a inverdade de um conhecimento, não a sua verdade, [...] é preciso evoluir para uma readaptação prodigiosa, superar o perigo, disciplinar-se nessa marcha sobre o fio de uma navalha. Talvez a muitos possa bastar o burguesismo da posição pragmatista, tão dentro da cômoda quotidianidade. Outros procurarão mais organicidade, mais gênio humano, mais domínio da vida (PILOTTO, 1973, p.30).

$\mathrm{Na}$ seqüência do raciocínio, citando Goethe, afirma que " "tenho por verdadeiro o pensamento que é fecundo para mim, liga-se ao resto do meu pensar e ao mesmo tempo me estimula', - uma 'verdade' que se mede pela sua significação para a vida" (PILOTTO, 1973, p.30). As idéias de Tolstoi e de Rousseau, que marcaram a sua formação e a sua decisão pela causa educacional, assim como a sua ampla indagação filosófica no período de maturidade serviram como suportes para a crítica às teorias educacionais que - ocupadas com o método pedagógico, o currículo, a administração ou o financiamento da educação - fragmentavam os olhares sobre o processo de formação do indivíduo. Para Pilotto a escola, a metodologia, o sistema de ensino são abstrações, pois "o que há objetivamente são seres singulares $e$ situações singulares” (PILOTTO, 1989, p.118).

Em Retorno ao Tema da Educação Nova, de 1966, alerta para o risco de o sociologismo passar a ser a única referencia teórica da Educação Nova:

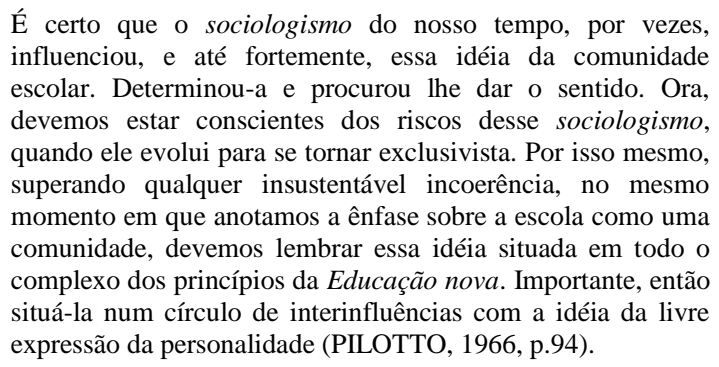

A liberdade, a individualidade, a força da vontade não se submetem às determinações de ordem social ou natural. Para ele, a formação do indivíduo não se resume a operações cognitivas e o homem não tem a sua condição existencial condicionada pelo meio social. A referência à presença 
do sociologismo na esfera educacional é precisa, pois são conhecidos os investimentos do Centro Brasileiro de Pesquisas Educacionais (CBPE), na segunda metade da década de cinqüenta e na década de sessenta, na gestão de Anísio Teixeira no Instituto Nacional de Estudos Pedagógicos (INEP), em torno da consolidação da pesquisa educacional a partir de aportes antropológicos e sociológicos. ${ }^{8}$

Se não recusarmos a idéia de um pensamento escolanovista, da homogeneidade teórica do movimento, da unidirecionalidade da polaridade entre liberais e católicos, não compreenderemos essas reações de Pilotto como evidências de um confronto que se produzia também no interior do movimento e que tinha na sua expressão teórica apenas uma das suas dimensões. O prestígio de seus protagonistas, a ocupação de espaços institucionais e, sobretudo, a direção dos processos de formação das novas gerações estava em disputa. $O$ embate não se resumiu à contraposição cientificismo e espiritualismo, pelo contrário, esteve muito mais acirrado entre aqueles que sustentaram visões materialistas e cientificistas. Pragmatistas, positivistas, funcionalistas e marxistas terçaram suas armas, contudo as divergências não impediram o trabalho conjunto em instituições como a $\mathrm{ABE}$, secretarias de governo e sobremaneira nos diversos fóruns nos quais a questão educacional encontrava-se em discussão, particularmente aqueles que tinham como propósito a definição de políticas públicas para educação. ${ }^{9}$

O posicionamento de Pilotto na discussão da Primeira Lei de Diretrizes e Bases da Educação Nacional evidencia essa unidade programática contra o que ele chamou de interesses da direita católica que, na primeira fase da discussão parlamentar, esteve restrita às manobras de bastidores, mas "quando sentiu sua força crescente, passou à ofensiva e jogou na mesa o Projeto Carlos Lacerda, em 1959, condensando toda uma posição de direita nítida e atrevida" (PILOTTO, 1966, p.8). Da parte das lideranças nacionais também não faltou apoio político a ele. Na sua gestão como Secretario de Estado de Educação e Cultura, entre 1949 e 1951, pressionado pela política clientelista que buscava na educação os meios para premiar aliados e retaliar adversários, Pilotto recebeu o apoio direto das lideranças nacionais, em especial na ocasião da promulgação da Lei Orgânica da Educação para o

\footnotetext{
8 Sobre esse tema ver Libânia Nacif Xavier, O Brasil como laboratório: Educação e Ciências Sociais no projeto dos centros brasileiros de pesquisa educacional CBPE/Inep/MEC (1950-1960). Bragança Paulista: Edusf, 1999. Além de FREITAS, M. C. História, Antropologia e a pesquisa educacional: itinerários intelectuais. São Paulo: Cortez, 2001.

9 Sobre a presença do marxismo no âmbito do movimento renovador, ver BRANDÃO Z. A intelligentsia educacional um percurso com Paschoal Lemme: por entre as memórias e as histórias da escola nova no Brasil. Bragança Paulista: Edusf, 1999.
} 
Estado do Paraná, quando Anísio Teixeira lhe escreveu dizendo: "trata-se de estatuto dos mais complexos que se têm feito entre nós e cuja estrutura é, sob vários aspectos, nova e complexa [...] Aí está um projeto que se constituirá um dos modelos para a experiência dos demais Estados. Felicito-o, vivamente, pela sua obra" (PILOTTO, 1989, p.70).

\section{À guisa de conclusões}

No Paraná, seguindo a tendência de polarização do plano nacional, dois projetos educativos principais se defrontaram: os católicos e os renovadores. Todavia, a constituição desses dois pólos no Estado assumiu dimensões irredutíveis ao cenário nacional, particularmente no que tange à constituição do campo dos renovadores. A ausência de uma hierarquia, de uma instituição de abrangência internacional com as características da Igreja Católica, fez com que o movimento renovador se identificasse e se organizasse sob a crítica do tradicionalismo, representado em grande parte pela pedagogia católica e pelo formalismo herbatiano, bem como sob um conjunto de pontos programáticos comuns, tais como o caráter público e laico da educação, a crítica à seletividade da escola, a profissionalização do professor, entre outros pontos que se justificavam, com maior ou menor coerência, a partir de corpos teóricos diferenciados e, mesmo, conflitantes.

Nesses termos, Pilotto encontrou no Movimento pela Escola Nova uma possibilidade de produzir uma profunda crítica das formas tradicionais de ensino - baseadas no formalismo do método, na capacidade mnemônica do aluno e na passividade do professor em relação ao conhecimento - e, assim, afirmar a sua concepção educativa baseada na liberdade, na autodeterminação e no poder da intuição e da vontade. A educação para a vida, no pensamento de Pilotto, não se resume ao utilitarismo propiciado pela instrumentalização técnica e científica, pois a vida, categoria chave na sua filosofia, expressa uma realidade profunda que, nem a ciência, nem a teologia são capazes de apreender. Talvez concebesse a arte, à medida que esta aguça a sensibilidade, como o lugar mais apropriado para despertar essa perspectiva de totalidade e de organicidade na compreensão e, sobretudo, na relação do homem com a natureza, com a sociedade e com o outro. Pilotto produziu uma concepção educativa que, na expressão de Hélio de Freitas Puglielli, não se ocupou da escola ou das pedagogias, mas do homem (PUGLIELLI, 1996, p.7).

As suas idéias contrastavam com a crescente cientificização do campo educacional nas décadas de cinqüenta e sessenta e, dessa forma, não repercutiram no debate pedagógico em âmbito nacional, ainda que, no plano estadual, tenham sido referência nos processos de formação de professores até a década de setenta do século passado. Ao contrário da Itália, que debateu e 
experimentou a hegemonia do espiritualismo no plano educativo, no Brasil a sua incidência foi pontual. Não obstante, reconhecê-la em nosso cenário permite, a meu ver, uma leitura no mínimo mais abrangente do Movimento pela Escola Nova no Brasil que, na expressão de Pilotto, não significou "apenas um plano para as escolas e para as classes, mas um espírito novo para a cultura" (PILOTTO, 1966, p.78). Permite também compreender o movimento renovador como resultado de disputas entre diferentes projetos formativos que, diante de situações específicas, produziu aproximações e rupturas, consensos e dissensos, cabendo ao historiador analisá-los e assim produzir o conhecimento histórico sobre esse movimento que tão profundamente marcou a educação brasileira.

A reflexão de Pilotto não gerou continuidades, pelo contrário, é um típico exemplo de descontinuidade na produção do pensamento educacional. Enfatizar a descontinuidade, discutir um projeto que foi preterido no embate teórico, político e institucional possibilita evitar a naturalização das formas de pensamento hegemônicas. Segundo Quentin Skinner

\begin{abstract}
O historiador do pensamento pode nos ajudar a apreciar até onde os valores incorporados em nosso atual modo de vida, e nossas atuais maneiras de pensar sobre esses valores, refletem uma série de escolhas feitas em épocas diferentes entre diferentes mundos possíveis. Essa consciência pode ajudar a libertar-nos do domínio de qualquer uma das explicações hegemônicas desses valores e de como eles devem ser interpretados e compreendidos. Munidos de uma possibilidade mais ampla, podemos nos distanciar dos compromissos intelectuais herdados e exigir um novo princípio de investigação sobre esses valores (SKINNER, 1999, p.93).
\end{abstract}

Em outros termos, permite perceber que existem escolhas, que é possível pensar de forma diferente daquela que se apresenta na cena cultural como único caminho sensato e racional, como evolução necessária de um processo.

\title{
FONTES HISTÓRICAS
}

PILOTTO, Erasmo._Memorial_(Manuscrito inédito de Pilotto), 1989.

.Obras. Curitiba: Imprimax, 1973. v.1

.Obras. Curitiba: Imprimax, 1976 v.2.

._Problemas de educação. Curitiba: Imprimax, 1969. 
VIEIRA, C. E. O Movimento pela Escola Nova...

. Que se exalte em cada mestre um sonho. (Discursos proferidos em diferentes solenidades de 1939 a 1965).

. Depoimento para o Museu da Imagem e do Som. Curitiba: [s.n., 19-].

\section{REFERÊNCIAS}

BALHANA, C. A. de F. Idéias em confronto. Curitiba: Grafipar, 1981.

BAKHTIN, M. Marxismo e filosofia da linguagem. 7. ed. São Paulo:

Hucitec, 1995.

BOAS, G. The history of ideas: an introduction. New York, 1969.

BEIRED, J. L. B. A função social dos intelectuais. In: AGGIO, Alberto (org.). Gramsci: a vitalidade de um pensamento. São Paulo: Unesp, 1998. P.121-132.

BRANDÃO, Z. A intelligentsia educacional um percurso com Paschoal Lemme: por entre as memórias e as histórias da escola nova no Brasil. Bragança Paulista: Edusf, 1999.

CARVALHO, M. M. C. de. Educação e política nos anos 20: a desilusão com a república e o entusiasmo com a educação. In: LORENZO, H. C de; COSTA, W. P. da. A década de 1920 e as origens do Brasil moderno. São Paulo: Unesp, 1997.

CARVALHO, M. M. C. de. Molde nacional e fôrma cívica: higiene, moral, e trabalho no projeto da Associação Brasileira de Educação (1924-1931). Bragança Paulista: Edusf, 1998.

CHARTIER, R. A história cultural: entre práticas e representações. Lisboa: Difel, 1990.

CONKIN, P. K. Intellectual history: past, present and future. In: DELZELL, C. F. The future of history. Nashville: [s.n.], 1977.

DARNTON, R. O beijo de lamourette. São Paulo: Companhia das Letras, 1990.

DIGGINS, J. P. The oyster and the pearl: the problem of contextualism in intellectual history. History and theory, v. 23, n.2. 1984.

DUNN, J. The identity of the history of ideas. Philosophy, n.43, p. 85-104. 1968.

FALCON, F. História das idéias. In: CARDOSO, C. F. et al. Domínios da história: ensaios da teoria e metodologia. Rio de Janeiro: Campus, 1997. 
FREITAS, M. C. (Org.). Memória intelectual da educação brasileira. Bragança Paulista: Edusf, 1999.

. História, Antropologia e a pesquisa educacional: itinerários

intelectuais. São Paulo: Cortez, 2001.

GRAMSCI , A. Quaderni del carcere. Torino: Einaudi, 1977.

. La formazione dell'uomo: scritti di pedagogia. Roma: Riuniti, 1967.

KELLEY, D. Horizons of intellectual history: retrospect, circumspect, prospect. Journal of the historyof ideas, v.48, n.1, jan/mar. 1987.

. What is happening to the history of ideas. Journal of the history of ideas, v. 51, n.1, p. 3-22, jan/mar. 1990.

KRIEGER, L. The autonomy of intellectual history. Journal of History of Ideas, n.34, 1973.

LAHUERTA, M. Gramsci e os intelectuais: entre cléricos, populistas e revolucionários. In: AGGIO, A. (Org.). Gramsci: a vitalidade de um pensamento. São Paulo: Unesp, 1998. p.133-158.

LAHUERTA, M. Os intelectuais e os anos 20: moderno, modernismo, modernização. In: LORENZO, H. C. de; COSTA, W. P. da. A década de 1920 e as origens do Brasil moderno. São Paulo: Unesp, 1997.

LEVICH, M. Interpretation in history: or what historians do philosofhers say. History and theory, v.24, n. 1. 1985.

MICELI, S. Intelectuais e classe dirigente no Brasil (1920-1945). Rio de janeiro: Difel, 1979.

MOTA, C. G. A ideologia da cultura brasileira: 1933-1974. São Paulo: Ática, 1994.

MIGUEL, M. E. B. A formação do professor e a organização social do trabalho. Curitiba: UFPR, 1997.

. O significado do trabalho de Erasmo Pilotto no cenário educacional paranaense. Curitiba, Educar em Revista, n.10, p.81-90. 1994.

PECAUT, D. Os intelectuais e a política no Brasil: entre o povo e a nação. São Paulo, Ática, 1990.

PUGLIELLI, H. de F. et al. Erasmo Pilotto. Curitiba: UFPR, 1996. (Série Paranaense n.7). 
SCHMIDT, M. A. M. dos S. Infância: sol do mundo. A primeira conferência nacional de educação e a construção da infância brasileira. Curitiba, 1997. Tese (Doutorado em História) - UFPR.

SKINNER, Q. Liberdade antes do liberalismo. São Paulo: Unesp, 1999. . Meaning and understanding in history of ideas. History and Theory, n.8, p. 3-53. 1969.

TRINDADE, E. M. de C. Clotildes e Marias: mulheres de Curitiba na $1^{\mathrm{a}}$ República. Curitiba: Fundação Cultural, 1996.

UNIVERSIDADE FEDERAL DO PARANÁ. Sistema de Bibliotecas. Normas para apresentação de documentos científicos. Curitiba: Ed da UFPR, 2000 .

VIEIRA, C. E. Historicismo, cultura e formação humana no pensamento de Antonio Gramsci. São Paulo, 1999. Tese (Doutorado em História e Filosofia da Educação)- Pontifícia Universidade Católica de São Paulo.

. Historicismo, cultura e formação humana no pensamento de Antonio Gramsci. In: REUNIÃO ANUAL DA ASSOCIAÇÃO NACIONAL DE PÓSGRADUAÇÃO E PESQUISA EM EDUCAÇÃO, 22., 1999. Caxambú. Anais... Caxambú: [s. n.], 1999.1 CD-ROM.

. Cultura e formação humana no pensamento de Antonio Gramsci.

Educação e Pesquisa: Revista da Faculdade de educação da USP, São Paulo, 1999, v.25, n.1, p. 51-66, jan/jun. 1999.

. Neopitagorismo e espiritualismo: a formação do pensamento de Erasmo Pilotto. In: I CONGRESSO BRASILEIRO DE HISTÓRIA DA EDUCAÇÃO, 2000, Rio de Janeiro. I Congresso Brasileiro de História da Educação: Educação no Brasil: História e historiografia. Rio de Janeiro: Sociedade Brasileira de História da Educação, 2000. 1 CD-ROM.

WINOCK, Michel. O século dos intelectuais. Rio de Janeiro: Bertrand Brasil, 2000.

XAVIER, Libânia Nacif. O Brasil como laboratório: Educação e Ciências Sociais no projeto dos centros brasileiros de pesquisa educacional CBPE/Inep/MEC (1950-1960). Bragança Paulista: Edusf, 1999. 